\title{
Determining the heritable component of dairy cattle foot lesions
}

\author{
A. M. Oberbauer, ${ }^{* 1}$ S. L. Berry, ${ }^{*}$ J. M. Belanger, ${ }^{*}$ R. M. McGoldrick, ${ }^{*}$ J. M. Pinos-Rodriquez, $†$ and T. R. Famula* \\ ${ }^{*}$ Department of Animal Science, One Shields Ave., University of California, Davis 95616 \\ †Instituto de Investigación de Zonas Desérticas, Llano San Luis Potosi, San Luis Potosi, México 78377
}

\section{ABSTRACT}

Lameness and hoof health affect dairy cows as an animal welfare issue, in decreased milk production, and in premature culling. Selection schemes for dairy cattle focus on sire contribution to milk production, with little consideration of the cow's physical structure or disease probability. On 3 commercial California dairies, 6 phenotypic binary hoof traits that contribute to lameness were recorded: white line disease, sole ulcer, other claw horn lesions, foot rot (interdigital phlegmon), foot warts (digital dermatitis), and other lesions. Monthly lactation records were collected from December 2006 to April 2009 with weekly observations of hoof lesions for lame and dry cows. In addition to hoof lesion information, data on cows $(\mathrm{n}=5,043)$ included parentage, birth date, freshening date, lactation number, and date of lameness diagnosis. The prevalence of hoof lesions ranged from a low of $2.2 \%$ (foot rot) to a high of $17.1 \%$ (foot warts). The farm environment increased the odds ratio depending upon the lesion. Lameness was more common in early lactation and as lactation number increased. Using a threshold model, heritabilities and repeatabilities were estimated for each binary trait. The heritability for risk varied by lesion, with the higher estimates being 0.40 (95\% confidence interval: $0.20-0.67$ ) for digital dermatitis and 0.30 (95\% confidence interval: 0.08-0.63) for sole ulcer. Including terms to account for cow productivity on either a 305-d mature-equivalent basis or a per-lactation basis had minimal effect on the heritability estimates, suggesting that selection for hoof health is not correlated with response to selection for greater milk production and that improvement could be made for both traits. The genetic component lends support for further genetic studies to identify loci contributing to some of the lesion phenotypes such as foot warts or sole ulcers, 2 of the top 3 causes of lameness in dairy cattle.

Key words: hoof disease, heritability, cow comfort, lameness

Received February 28, 2012.

Accepted September 7, 2012.

${ }^{1}$ Corresponding author: amoberbauer@ucdavis.edu

\section{INTRODUCTION}

The dairy industry faces increasing production costs and environmental concerns, and strategies that address the need for reduced input and greater outputs are essential. Lameness is an animal welfare issue and causes lowered milk production. Lameness is one of the top reasons why dairy cattle are culled prematurely, following infertility and mastitis (Boettcher et al., 1998). In California, the average culling rate in 2010 was $38.9 \%$ (California Dairy Herd Improvement Association, 2010); this represents a significant cost to the producer and contributes to the overall carbon footprint of a dairy due to the environmental costs associated with raising replacement dairy heifers. Genetic selection schemes for dairy cattle focus on the marketable product (pounds of milk, fat, and protein produced) and reproductive traits (Weigel, 2006), often ignoring other traits that might improve a cow's productive lifespan. In contrast, the genetics of lameness and hoof health has been little studied (Harder et al., 2006) yet represents an important aspect of dairy management.

Lameness affects overall cow comfort. Risk factors for lameness include freestall housing, bedding, and floor composition (Cook and Nordlund, 2009; Fjeldaas et al., 2011). Diet contributes to the manifestation of sole ulcers and white line disease (Cook and Nordlund, 2009; Buch et al., 2011), whereas hygiene and infectious agents contribute to digital dermatitis, foot rot, and heel horn erosion (Evans et al., 2009; Buch et al., 2011). Sole ulcers, foot rot, and double sole have been shown to be most correlated with poor locomotion scores (Tadich et al., 2010), although the presence of hoof lesions does not always cause clinical lameness, suggesting that hoof lesions are more common than gait alterations would suggest (Berry, 2001; Tadich et al., 2010).

The prevalence of lameness in dairy cattle as reported in the literature is as high as 54\% (reviewed in Ward, 2009), although a more common estimate is between 15 and 25\% (Cook and Nordlund, 2009). Prevalence of hoof lesions can be as high as 64\% (Sogstad et al., 2005). Costs associated with lameness include a delay in return to estrus, reduced feed intake, lower overall BCS (Walker et al., 2008), reduced milk production 
(Green et al., 2002; Ward, 2009), exhibition of obvious discomfort (Galindo and Broom, 2002), and increased labor needed for treatment. Ward (2009) stated, "Mastitis and lameness are the biggest causes of financial loss to UK dairy farmers." The economic impact of each lameness case was estimated to be $€ 192$ in a typical Danish dairy herd (Ettema and Ostergaard, 2006). Investigators in the United States modeled specific hoof lesions and determined the approximate cost per case (US\$) for sole ulcers, foot warts, and foot rot to be $\$ 216, \$ 133$, and $\$ 121$, respectively (Cha et al., 2011). The variable costs and etiologies of hoof lesions clearly demonstrate the importance of considering different underlying causes of lameness. The economic loss, animal welfare aspect, and the public perception of lameness are of enormous concern for the multi-billion-dollar dairy industry.

Published work investigating heritabilities of leg and hoof conformation (reviewed in Shook, 2006; Buitenhuis et al., 2007) have found low heritabilities for those traits, ranging from 0.05 to 0.22 (Koenig et al., 2005; Harder et al., 2006; Laursen et al., 2009). Accurate heritability estimates rely upon sufficiently large populations and consistent lameness diagnosis and classification; several published studies have limitations in these 2 areas. Nevertheless, whole-genome scans have been performed, with the most recent and extensive being done on Holsteins using a granddaughter design and 327 microsatellite markers offering $\sim 8 \mathrm{cM}$ coverage with the objective of identifying QTL associated with lameness and leg conformation (Buitenhuis et al., 2007). The authors reported the presence of several QTL associated with leg and hoof conditions, although they note that the QTL identified did not correspond to QTL previously reported in the literature.

We characterized the prevalence of the predominant hoof lesions in dairy cattle on 3 commercial dairies in California, profiled the occurrence of the lesions during several lactations, and assessed the heritability of those lesions with the aim of evaluating the genetic contribution to hoof lesion expression. The data provide heritability estimates indicating that concerted selection may enhance the longevity of the cow in the production herd.

\section{MATERIALS AND METHODS}

\section{Animals}

Monthly lactation records were collected from 3 California dairies from December 2006 to April 2009, along with weekly hoof health evaluations of cows finishing their lactations (dry) and lactating cattle that were visibly lame. That is, at weekly intervals, the hooves of cows at the end of lactation were trimmed and evaluated, as were those of any lactating cow deemed lame. Data collection was in accordance with the University of California, Davis Institution Animal Care and Use Committee guidelines for privately owned animals. The dairies were milking 1,400 to 1,600 cows each, and all lactating cows were housed in freestalls. All cows were fed rations formulated by a nutrition consultant. Hoof lesions observed by the hoof trimmer were recorded as binary traits. Recorded with lesion status were parity, parentage, birth date, freshening date, and lesion evaluation date. Lesions on all 3 dairies were identified and recorded by the same trained, experienced hoof trimmer, ensuring a consistent classification of the observed phenotypes. The data set has repeated records for a given animal because lesion status could change from one observation date to the next. The lesions recorded were white line disease; sole ulcer; foot rot; foot warts found on any hoof; lameness due to worn feet, injury, double sole, or upper limb cause (collectively considered "other lesions"); and any sole abscess, sole fracture, heel ulcer, or wall abscess (collectively considered "other claw horn lesions"). Phenotypic and pedigree data from the cooperating herds were merged for a final data set of 12,007 recorded observations on 5,043 cows. Table 1 summarizes the observations (affected and unaffected) for the lesions across parities, and Table 2 summarizes the number of observations across the stage of lactation.

Additional descriptive information was collected at the same time that lameness phenotypes were observed and recorded. Among these was stage of lactation at the time of observation. Subsequently, observations were categorized into 1 of 7 mutually exclusive stage of lactation classes: dry cows, 0-60 DIM, 61-120 DIM, 121-180 DIM, 181-240 DIM, 241-300 DIM, and >300 DIM. Similarly, lameness observations were classified into 1 of 4 seasons of freshening class: winter (December, January, February), spring (March, April, May), summer (June, July, August), and fall (September, October, November). Furthermore, to incorporate evaluation of the effect of milk production on the risk of lameness, lameness phenotypes were classified into 1 of 3 tertiles, within each stage of lactation class (effectively creating a stage $\times$ milk level interaction term). Records were ranged into 3 milk production tertiles based on finding that milk test-day closest to the date of lameness observation. Then, records were classified into low, medium, or high tertile based on the total amount of milk produced up to that point in lactation. Cutpoints for the tertiles were determined from the observed total milk values, changing from one stage of lactation to the next. Specifically, cows were assigned to 1 of 3 groups (low, medium, or high) based upon the lactation the 
Table 1. Affected and normal observations for lesions (actual number observed) based upon parity ${ }^{1}$

\begin{tabular}{|c|c|c|c|c|c|c|}
\hline Parity & \multicolumn{6}{|c|}{ Lesion, \% of total (no.) } \\
\hline 2 & $1.73(208)$ & $0.58(70)$ & $0.57(69)$ & $0.84(101)$ & 0.97 (117) & $4.41(529)$ \\
\hline 3 & $1.67(201)$ & $0.88(106)$ & $0.42(51)$ & $1.01(121)$ & 0.98 (118) & $4.24(509)$ \\
\hline $4+$ & $3.27(393)$ & $2.38(286)$ & $0.77(92)$ & $1.74(209)$ & $1.45(174)$ & $5.44(653)$ \\
\hline
\end{tabular}

${ }^{1}$ The data set represented 12,007 recorded observations on 5,043 cows, with some cows having more than one lesion recorded.

animal had just completed. Dry cows were also classified into milk production groups, permitting the assessment of the effect of level of milk production on hoof disease. A second analysis of the effect of milk production was performed using a 305-d mature-equivalent milk yield basis (305ME) for each cow to categorize the cows into tertiles. The models used for analysis all included terms for the season of freshening and the DIM at the time of hoof evaluation. Thus, the probabilities of risk of hoof lesions were determined as a function of lactation stage (DIM), lactation stage and milk produced (DIM/Milk), and lactation stage and the 305-d mature-equivalent yield (DIM/305ME). We did not include a term for the month (or season) of observation, even though this is a potential fixed effect. However, classification on month of observation was confounded with the combination of DIM and season of freshening. Accordingly, a contemporary group based on either system (i.e., month of data recording vs. month of freshening plus DIM) would lead to an equivalent grouping strategy.

\section{Analyses}

The analysis made use of a logit link function to tie the binomial disease response (i.e., yes/no) to potential explanatory variables. That is, the probability of lesion for the $j$ th observation on the $i$ th cow $\left(p_{i j}\right)$ can be modeled as

$$
\begin{aligned}
\operatorname{logit}\left(p_{i j}\right)= & \log \left[p_{i j} /\left(1-p_{i j}\right)\right]=\mu+\boldsymbol{\beta}_{i j}^{\prime} x_{i j} \\
& +a_{i}+p e_{i}+e_{i j}
\end{aligned}
$$

Table 2. Distribution of observations (affected and normal) across DIM

\begin{tabular}{lc}
\hline DIM class & No. of observations \\
\hline $0-60$ & 883 \\
$61-120$ & 662 \\
$121-180$ & 781 \\
$181-240$ & 792 \\
$241-300$ & 1,709 \\
$>300$ & 2,891 \\
Dry & 4,289 \\
\hline
\end{tabular}

where $\mu$ is a constant common to all animals; $x_{i j}$ is a set of recorded nongenetic contributors to lesion status (i.e., herd, parity number, DIM class, season of freshening, and tertile of milk production within DIM class for the $j$ th observation on the $i$ th cow); $\boldsymbol{\beta}_{i j}$ is the unknown vector of effects associated with these nongenetic contributors; $a_{i}$ is the additive genetic contribution to lesion status for the $i$ th cow; $p e_{i}$ is the permanent environmental contribution to lesion status associated with the $i$ th cow; and $e_{i j}$ is the unknown residual particular to each observation. In addition, $a_{i}$ was assumed to be sampled from vector $\mathbf{a}$, a vector of breeding values for all 14,461 animals represented in the data set, of which 5,043 had recorded observations, from a multivariate normal density with mean zero and covariance $\mathbf{A} \sigma_{a}^{2}$, with $\mathbf{A}$ being the numerator relationship matrix, the $p e_{i}$ to be sampled from the vector $\mathbf{p}$, a vector of permanent environmental effects of length 5,043, following a multivariate normal density, independent of $\mathbf{a}$, with mean zero and variance $I \sigma_{p e}^{2}$, and the residuals to follow from a normal density with mean zero and variance $I$ (note, the residual variance is assumed to be 1.0). The objective was to estimate the unknown vector $\boldsymbol{\beta}_{i j}$, along with the unknown variances $\sigma_{a}^{2}$ and $\sigma_{p e}^{2}$. With that, the heritability $\left(h^{2}\right)$ of each lesion can also be estimated:

$$
h^{2}=\frac{\sigma_{a}^{2}}{\left(\sigma_{a}^{2}+\sigma_{p e}^{2}+1\right)},
$$

as can the repeatability $(r)$ of each lesion measure:

$$
r=\frac{\left(\sigma_{a}^{2}+\sigma_{p e}^{2}\right)}{\sigma_{a}^{2}+\sigma_{p e}^{2}+1} .
$$

A Bayesian framework, a strategy of considerable power and plasticity, was used to evaluate these unknown values (Sorensen and Gianola, 2002). The public domain package MCMCglmm (Hadfield, 2010), avail- 
able through the language $\mathrm{R}$ ( $\mathrm{R}$ Development Core Team, 2011) was used. The prior distributions for the putative fixed effects (the nongenetic terms in $\boldsymbol{\beta}$ ) were independent normal densities with null means and variances of $\mathrm{e}^{10}$; that is, a diffuse normal prior. The prior distribution for the variance components $\left(\sigma_{a}^{2}\right.$ and $\left.\sigma_{p e}^{2}\right)$ was assumed to be an inverse-Wishart density. For single variance components, the inverse-Wishart is governed by 2 parameters, $V$ and $\nu(n u)$, in the notation of Hadfield (2010). The distribution is right-skewed when $\nu$ is small, with a mode of $V \times v /(\nu+2)$. For our analyses, we set $\nu=0.002$ to permit a long flat rightskewness, effectively creating a diffuse prior for the unknown variances $\sigma_{a}^{2}$ and $\sigma_{p e}^{2}$. The MCMCglmm package (Hadfield, 2010) refers to $\nu$ as the "degree of belief parameter," where the smaller the value, the weaker one's prior belief in the value $V$. As implied by the use of MCMCglmm package, estimates of the posterior density for the unknown parameters were generated through a Monte Carlo Markov chain. Each lesion was evaluated with 3 chains, each starting at disperse values for the unknown variances (i.e., the $V$ parameter of the inverse-Wishart was set at $0.05,0.5$, or 1.0 for $\sigma_{a}^{2}$ and $\sigma_{p e}^{2}$ with $\left.\nu=0.002\right)$. Convergence of the chains was examined through trace plots, making use of the $\mathrm{R}$ package coda (Plummer et al., 2006) and computation of the Gelman-Rubin statistic (Gelman and Rubin, 1992). Each chain was run for 500,000 rounds with a burn-in of 50,000 rounds and a thinning interval of 100 (creating a single-chain sample of 4,500 values). In this scenario, all lesions had chains that mixed well (all Gelman-Rubin statistics were between 1.00 and 1.03), with the absolute value of all autocorrelations for parameters below 0.07 .

\section{RESULTS}

Parameter estimates and odds ratios (OR) for the lesions when farm, parity, calendar season, and DIM are included in the DIM model are presented in Table 3. The OR are expressed relative to a specific reference group for each explanatory variable; for example, relative to farm $\mathrm{A}$, parity 1 , the winter season, and 0-60 DIM. The specific reference group is not included in the tables. Supplemental Tables 1 and 2 (http:// www.journalofdairyscience.org/) present the parameter estimates when the DIM/Milk or DIM/305ME models, respectively, were used.

Farm had an effect on sole ulcer, foot rot, other claw horn lesions, and foot warts, regardless of the model. As evidenced by the $95 \%$ highest density probability, farm C had a higher risk of sole ulcers and foot warts, whereas farm B had a much lower risk for foot warts. Likewise, farms B and C had greater risk for other claw horn lesions but a lesser risk for foot rot compared with farm A (indicated by the negative probability densities that do not overlap zero).

Risk of white line disease, sole ulcer, claw horn lesions, and foot warts increased with increasing parity across the 3 models. Season of freshening had little or no effect on the observation of any hoof traits evaluated.

Peak lactation was associated with greater risk of sole ulcer and claw horn lesions, foot rot was most often observed in early lactation, and white line disease was reduced in late lactation. Days in milk had no effect on other claw horn lesions and foot warts, except that cows in late lactation or dry ( $>300 \mathrm{~d})$ had the least risk for any recorded lesion (Table 3 ).

Accounting for milk production in the model (Figure 1 and Supplemental Tables 1 and 2; available online at http://www.journalofdairyscience.org/), we observed a similar profile for the lesions. Specifically, sole ulcers and claw horn lesions were observed most frequently near peak lactation, foot rot was observed most frequently in early lactation, and white line disease decreased across the lactation period regardless of whether a cow was classified as a low or high producer. Observed foot wart prevalence was also not affected by milk production. For other claw horn lesions, only the model accounting for milk production showed a reduction in risk as lactation progressed, although it was independent of the volume of milk produced. These findings indicate that the volume of milk produced was separable from the other factors that affect hoof lesion prevalence.

Heritability estimates (Table 4) for claw horn lesions and other claw horn lesions were low, ranging from 0.03 to 0.16 across all models; foot rot heritability estimates were variable (0.09 to 0.38 ) and had the largest $95 \%$ CI (0.00-0.72). In contrast, heritability estimates for white line disease and sole ulcer ranged from 0.24 to 0.30 (with a $95 \%$ CI encompassing 0.10 to 0.63 ) regardless of milk production. The heritability estimate of foot warts was 0.40 (95\% CI: 0.20 to 0.67 ) when milk production was not included, and was 0.33 (95\% CI: 0.17 to 0.55 ) when milk production was included in the model. The repeatability estimates were, in general, $>0.50$ across all lesions and models.

\section{DISCUSSION}

The prevalence of the common hoof lesions in 3 commercial California dairies was determined over a 29 -mo 
Table 3. Posterior modes [95\% highest probability density interval] and odds ratios (OR) for parameter values across the 6 phenotypic binary hoof lesion categories including DIM only (DIM model) ${ }^{1}$

\begin{tabular}{|c|c|c|c|c|c|c|c|c|c|c|c|c|}
\hline \multirow[b]{2}{*}{ Item } & \multicolumn{2}{|c|}{ White line disease } & \multicolumn{2}{|l|}{ Sole ulcer } & \multicolumn{2}{|l|}{ Foot rot } & \multicolumn{2}{|c|}{ Claw horn lesions } & \multicolumn{2}{|l|}{$\begin{array}{l}\text { Other claw } \\
\text { horn lesions }\end{array}$} & \multicolumn{2}{|c|}{ Foot warts } \\
\hline & Solution & OR & Solution & OR & Solution & OR & Solution & OR & Solution & OR & Solution & OR \\
\hline Intercept & $\begin{array}{l}-2.43 \\
{[-2.72 ;-2.14]}\end{array}$ & & $\begin{array}{l}-8.2 \\
{[-9.26 ;-7.2]}\end{array}$ & & $\begin{array}{l}-1.98 \\
{[-2.44 ;-1.57]}\end{array}$ & & $\begin{array}{l}-4.62 \\
{[-5.2 ;-4.08]}\end{array}$ & & $\begin{array}{l}-4.68 \\
{[-5.3 ;-4.11]}\end{array}$ & & $\begin{array}{l}-2.94 \\
{[-3.37 ;-2.53]}\end{array}$ & \\
\hline \multicolumn{13}{|l|}{ Dairy } \\
\hline B & $\begin{array}{l}0.42 \\
{[0.23 ; 0.61]}\end{array}$ & 1.5 & $\begin{array}{c}0.33 \\
{[-0.16 ; 0.84]}\end{array}$ & 1 & $\begin{array}{l}-1.58 \\
{[-2.01 ;-1.19]}\end{array}$ & 0.2 & $\begin{array}{l}-0.2 \\
{[-0.52 ; 0.11]}\end{array}$ & 1 & $\begin{array}{l}1.8 \\
{[1.43 ; 2.19]}\end{array}$ & 6.1 & $\begin{array}{l}-4.62 \\
{[-5.2 ;-4.08]}\end{array}$ & 0.01 \\
\hline $\mathrm{C}$ & $\begin{array}{l}0.48 \\
{[0.29 ; 0.67]}\end{array}$ & 1.6 & $\begin{array}{l}1.22 \\
{[0.77 ; 1.7]}\end{array}$ & 3.39 & $\begin{array}{l}-0.7 \\
{[-1 ;-0.42]}\end{array}$ & 0.5 & $\begin{array}{l}-0.01 \\
{[-0.3 ; 0.29]}\end{array}$ & 1 & $\begin{array}{l}1.2 \\
{[0.81 ; 1.6]}\end{array}$ & 3.3 & $\begin{array}{l}1.29 \\
{[1.04 ; 1.54]}\end{array}$ & 3.63 \\
\hline \multicolumn{13}{|l|}{ Parity } \\
\hline & {$[0.33 ; 0.72]$} & & {$[0.76 ; 1.95]$} & & {$[0.25 ; 0.9]$} & & {$[0.38 ; 1.13]$} & & {$[-0.23 ; 0.46]$} & & {$[0.63 ; 1.09]$} & \\
\hline 3 & $\begin{array}{l}0.7 \\
{[0.49 ; 0.91]}\end{array}$ & 2 & $\begin{array}{l}2.05 \\
{[1.45 ; 2.7]}\end{array}$ & 7.77 & $\begin{array}{c}0.26 \\
{[-0.09 ; 0.62]}\end{array}$ & 1 & $\begin{array}{l}1.15 \\
{[0.77 ; 1.56]}\end{array}$ & 3.2 & $\begin{array}{c}0.3 \\
{[-0.06 ; 0.68]}\end{array}$ & 1 & $\begin{array}{l}1.3 \\
{[1.02 ; 1.57]}\end{array}$ & 3.67 \\
\hline $4+$ & $\begin{array}{l}1.02 \\
{[0.82 ; 1.23]}\end{array}$ & 2.8 & $\begin{array}{l}3.38 \\
{[2.76 ; 4.05]}\end{array}$ & 29.4 & $\begin{array}{l}0.47 \\
{[0.13 ; 0.82]}\end{array}$ & 1.6 & $\begin{array}{l}1.49 \\
{[1.12 ; 1.87]}\end{array}$ & 4.4 & $\begin{array}{l}0.47 \\
{[0.12 ; 0.83]}\end{array}$ & 1.6 & $\begin{array}{l}1.41 \\
{[1.11 ; 1.71]}\end{array}$ & 4.1 \\
\hline \multicolumn{13}{|l|}{ Season } \\
\hline Spring & $\begin{array}{c}0.05 \\
{[-0.14 ; 0.24]}\end{array}$ & 1 & $\begin{array}{l}-0.08 \\
{[-0.53 ; 0.36]}\end{array}$ & 1 & $\begin{array}{l}-0.32 \\
{[-0.66 ; 0.02]}\end{array}$ & 1 & $\begin{array}{c}0.28 \\
{[-0.07 ; 0.62]}\end{array}$ & 1 & $\begin{array}{c}0.1 \\
{[-0.26 ; 0.46]}\end{array}$ & 1 & $\begin{array}{l}-0.05 \\
{[-0.3 ; 0.21]}\end{array}$ & 1 \\
\hline Summer & {$[-0.16 ; 0.21]$} & 1 & $\begin{array}{l}-0.41 \\
{[-0.86 ; 0.04]}\end{array}$ & 1 & {$[-0.38 ; 0.24]$} & 1 & $\begin{array}{l}0.12 \\
{[-0.21 ; 0.45]}\end{array}$ & 1 & $\begin{array}{l}0.19 \\
{[-0.15 ; 0.54]}\end{array}$ & 1 & {$[-0.28$} & 1 \\
\hline Fall & $\begin{array}{c}0.01 \\
{[-0.17 ; 0.2]}\end{array}$ & 1 & $\begin{array}{l}-0.38 \\
{[-0.81 ; 0.06]}\end{array}$ & 1 & {$[-0.02 ; 0.29]$} & 1 & $\begin{array}{l}0.18 \\
{[-0.15 ; 0.52]}\end{array}$ & 1 & $\begin{array}{l}0.11 \\
{[-0.25 ; 0.47]}\end{array}$ & 1 & $\begin{array}{l}-0.22 \\
{[-0.48 ; 0.04]}\end{array}$ & 1 \\
\hline \multicolumn{13}{|l|}{ DIM } \\
\hline $61-120$ & $\begin{array}{l}-0.08 \\
{[-0.34 ; 0.17]}\end{array}$ & 1 & $\begin{array}{l}1.49 \\
{[0.88 ; 2.1]}\end{array}$ & 4.43 & $\begin{array}{l}-0.6 \\
{[-0.97 ;-0.25]}\end{array}$ & 0.6 & $\begin{array}{c}0.21 \\
{[-0.26 ; 0.7]}\end{array}$ & 1 & $\begin{array}{c}0.02 \\
{[-0.45 ; 0.5]}\end{array}$ & 1 & $\begin{array}{c}0.17 \\
{[-0.24 ; 0.57]}\end{array}$ & 1 \\
\hline $121-180$ & $\begin{array}{l}-0.03 \\
{[-0.27 ; 0.21]}\end{array}$ & 1 & $\begin{array}{l}1.85 \\
{[1.27 ; 2.44]}\end{array}$ & 6.36 & {$[-1.09$} & 0.3 & $\begin{array}{l}0.82 \\
{[0.39 ; 1.25]}\end{array}$ & 2.3 & {$[-0.76$} & 0.5 & $\begin{array}{l}-0.17 \\
{[-0.56 ; 0.23]}\end{array}$ & 1 \\
\hline $181-240$ & $\begin{array}{l}-0.19 \\
{[-0.43 ; 0.05]}\end{array}$ & 1 & $\begin{array}{l}1.61 \\
{[1.03 ; 2.2]}\end{array}$ & 5 & {$[-1.7 ;-0.86]$} & 0.3 & $\begin{array}{l}0.49 \\
{[0.06 ; 0.93]}\end{array}$ & 1.6 & $\begin{array}{l}-0.25 \\
{[-0.69 ; 0.19]}\end{array}$ & 1 & {$[-0.25$} & 1 \\
\hline $241-300$ & {$[-1.38$ - $1.61 ;-1.15]$} & 0.3 & $\begin{array}{l}-0.11 \\
{[-0.68 ; 0.47]}\end{array}$ & 1 & $\begin{array}{l}-2.31 \\
{[-2.82 ;-1.87]}\end{array}$ & 0.1 & {$[-1.04$} & 0.4 & {$[-1.96$} & 0.1 & {$[-0.72$} & 0.49 \\
\hline$>300$ & {$[-1.6$} & 0.2 & $\begin{array}{l}-0.88 \\
{[-1.43 ;-0.34]}\end{array}$ & 0.41 & $\begin{array}{l}-2.43 \\
{[-2.87 ;-2.04]}\end{array}$ & 0.1 & {$[-1.47$} & 0.2 & $\begin{array}{l}-2.14 \\
{[-2.52 ;-1.76]}\end{array}$ & 0.1 & $\begin{array}{l}-0.65 \\
{[-0.96 ;-0.35]}\end{array}$ & 0.52 \\
\hline \multicolumn{13}{|l|}{ Variance } \\
\hline Animal & $\begin{array}{l}0.5 \\
{[0.2 ; 0.91]}\end{array}$ & & $\begin{array}{l}1.9 \\
{[0.5 ; 4.07]}\end{array}$ & & $\begin{array}{l}0.38 \\
{[0 ; 1.51]}\end{array}$ & & $\begin{array}{l}0.31 \\
{[0.03 ; 0.92]}\end{array}$ & & $\begin{array}{l}0.58 \\
{[0.03 ; 1.78]}\end{array}$ & & $\begin{array}{l}1.9 \\
{[0.94 \cdot 3.29]}\end{array}$ & \\
\hline $\mathrm{PE}^{2}$ & 0.6 & & 3.52 & & 1.25 & & 1.42 & & 2.4 & & 1.89 & \\
\hline & {$[0.22 ; 0.96]$} & & {$[1.25 ; 5.55]$} & & {$[0.03 ; 2.33]$} & & {$[0.63 ; 2.28]$} & & {$[1.05 ; 3.58]$} & & {$[0.59 ; 2.89]$} & \\
\hline
\end{tabular}




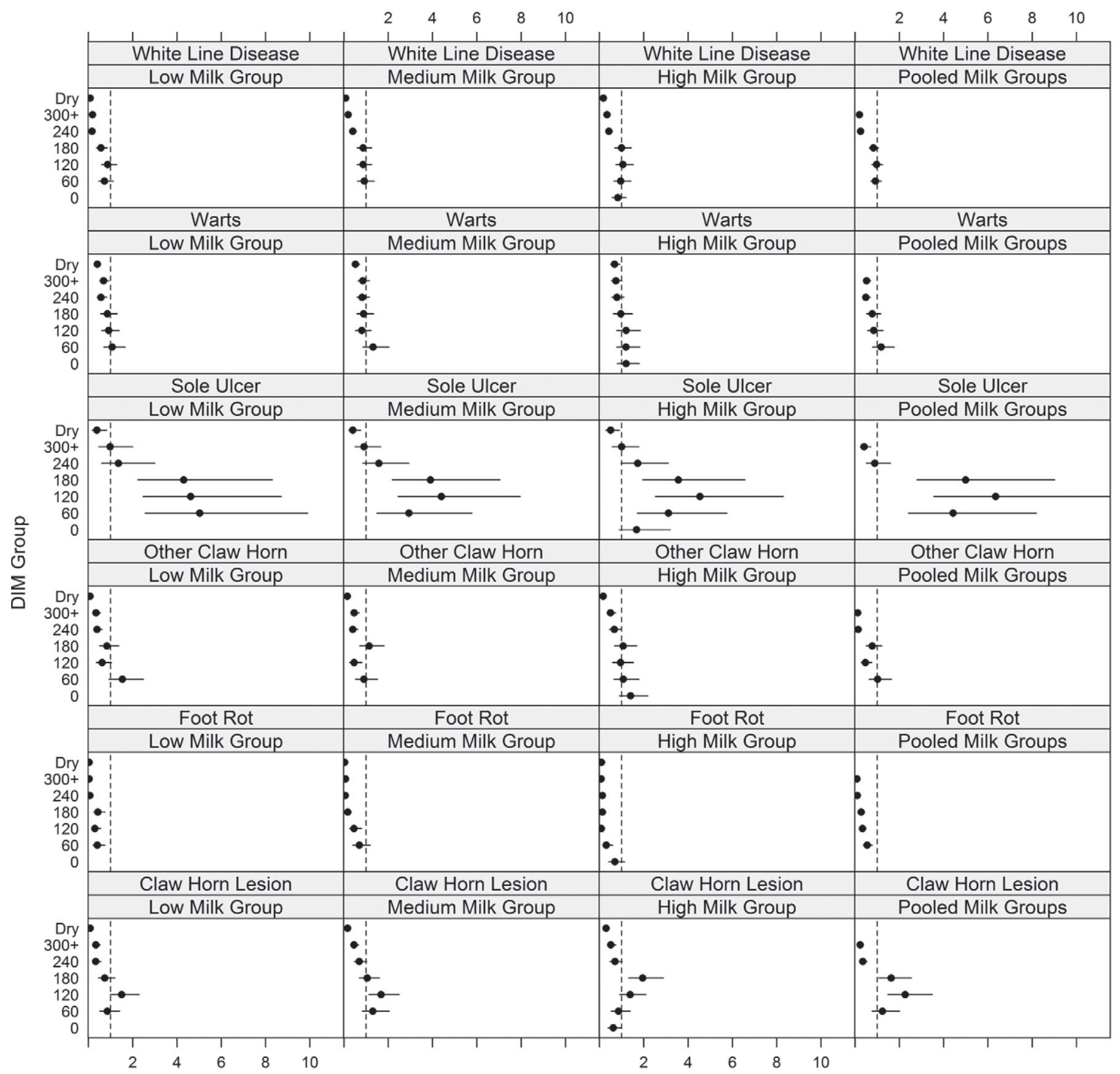

OR Estimate

Figure 1. Posterior modes for the odds ratios (OR), including the $95 \%$ highest probability density interval, for the 6 binary hoof lesion categories classified by DIM class and milk production tertile (low, medium, high; including the analysis with milk level removed from the analysis). The vertical dashed line at $\mathrm{OR}=1.0$ indicates significance.

period. Farm management contributed to the expression of particular lesions. The farm having a greater proportion of older cows in the herd (farm C; Supplemental Table 3; http://www.journalofdairyscience. org/) had the greatest risk for sole ulcers and foot warts, lesions that increase in prevalence with increasing parity. The farm with the younger milking herd population (farm B) had a lower risk for both lesions. Management played a role in the "other claw lesions" category, which includes injury; one farm had lower risk 
Table 4. Comparison of heritability and repeatability [95\% highest probability density interval] among the 3 models accounting for DIM, DIM with milk production (Milk), or DIM with 305-d mature equivalent milk production (DIM/305ME)

\begin{tabular}{llcc}
\hline Lesion & Model & Heritability & Repeatability \\
\hline White line disease & DIM & $0.24[0.10 ; 0.42]$ & $0.52[0.45 ; 0.58]$ \\
& DIM/Milk & $0.26[0.09 ; 0.42]$ & $0.54[0.48 ; 0.61]$ \\
Sole ulcer & DIM/305ME & $0.21[0.06 ; 0.41]$ & $0.52[0.44 ; 0.59]$ \\
& DIM & $0.30[0.08 ; 0.63]$ & $0.84[0.80 ; 0.88]$ \\
DIM/Milk & $0.26[0.06 ; 0.51]$ & $0.73[0.67 ; 0.79]$ \\
Foot rot & DIM/305ME & $0.25[0.06 ; 0.57]$ & $0.74[0.68 ; 0.79]$ \\
& DIM & $0.14[0.00 ; 0.58]$ & $0.61[0.47 ; 0.72]$ \\
Claw horn lesions & DIM/Milk & $0.09[0.00 ; 0.61]$ & $0.68[0.55 ; 0.78]$ \\
& DIM/305ME & $0.38[0.01 ; 0.72]$ & $0.63[0.46 ; 0.76]$ \\
Other claw horn lesions & DIM & $0.11[0.01 ; 0.33]$ & $0.63[0.52 ; 0.71]$ \\
& DIM/Milk & $0.03[0.00 ; 0.29]$ & $0.44[0.33 ; 0.54]$ \\
DIM/305ME & $0.06[0.00 ; 0.31]$ & $0.50[0.39 ; 0.59]$ \\
Foot warts & DIM & $0.14[0.01 ; 0.45]$ & $0.75[0.68 ; 0.80]$ \\
& DIM/Milk & $0.05[0.00 ; 0.26]$ & $0.61[0.54 ; 0.67]$ \\
& DIM/305ME & $0.16[0.02 ; 0.51]$ & $0.63[0.56 ; 0.71]$ \\
& DIM & $0.40[0.20 ; 0.67]$ & $0.79[0.76 ; 0.82]$ \\
& DIM/Milk & $0.32[0.17 ; 0.52]$ & $0.66[0.61 ; 0.69]$ \\
& DIM/305ME & $0.33[0.18 ; 0.55]$ & $0.66[0.62 ; 0.70]$ \\
\hline
\end{tabular}

for other claw horn lesions but a greater risk for foot rot, possibly reflecting different approaches to hygiene (Evans et al., 2009).

The high repeatability estimates for all recorded lesions suggest that once a cow is diagnosed with a lesion she will be more likely to exhibit the lesion again. Although the repeatability may indicate a strong environmental component that influences long-term lesion status, when coupled with the substantial heritability estimates for sole ulcer and foot warts, the data support a genetic component that enhances the repeated expression of lesions.

The hoof lesions recorded in this study are those that result in observable lameness and are known to reduce milk production, require treatment, and affect animal welfare. Overall, the dairy cattle on the 3 farms exhibited a $39.9 \%$ prevalence of a lameness-causing lesion across all observations, consistent with Main et al. (2010); foot warts were the greatest contributor, representing $17.1 \%$ of the observed lesions. This study demonstrated that some lesions have a higher association with the farm environment, which includes varied feeding, hygiene, and health management regimens. Changing facility management may reduce the prevalence of sole ulcer, foot rot, injuries, and foot warts, although attempts to account for herd management have been inconclusive (Koenig et al., 2005). It is notable that sole ulcers and foot warts also had the highest estimated heritability. With a significant heritable component to those lesions, the sires selected at some farms may contribute to the increased lesion observation. These same lesions increase in prevalence with increasing parity or age (also seen in Koenig et al., 2005), and farms with older animals may have a higher incidence.
Surprisingly, season of freshening did not affect lesion observations (one might have expected a relationship for the rainy or dry season). As shown by other studies (Koenig et al., 2005), lesions are observed with greater frequency during the peak and persistent milking phase.

Our goal was to evaluate the duration and degree of lactation stress on hoof lesions in the risk and heritability analyses. This could be captured by DIM and cumulative level of milk production on the day of hoof evaluation. The simplest approach might have been to include in the model a regression on these continuous covariates; however, multicollinearity exists between these 2 variables. We chose instead to create mutually exclusive categories to group observations by DIM class and tertile of cumulative milk production. This, too, is not without the risk of pooling data points into groups better left in different levels. Nevertheless, we used this grouping strategy to include measures of both duration (DIM) and degree (cumulative milk level) in our analysis, rather than risk the variance inflation that comes with correlated covariates. Moreover, this discrete approach should be less sensitive to the fluctuations in sample size across DIM groups, a limitation brought on by the nature of the hoof-trimming practices of the cooperating herds.

Heritability estimates for foot rot, claw horn lesions, and other claw lesions were similar to those estimated for linear leg traits in Holstein cattle (Zink et al., 2011). The high variability of the estimate of foot rot could be due to differences in the level of hygiene and the possibility of trauma to the interdigital skin on the dairy with the highest incidence. In contrast to recent published work in other countries that reported heritabilities ranging from 0.10 to 0.22 (van der Waaij et 
al., 2005; van der Linde et al., 2010), heritabilities for sole ulcer and foot warts were much higher on these 3 California dairies, indicating that selection against those traits may reduce lameness caused by these lesions. The higher heritability observed in the present study may reflect that all farms had similar housing and consistent phenotypic classification of the lesions. Despite the limitation of a small data set precluding a bivariate genetic analysis to estimate genetic correlations, using milk yield as covariate allowed inspection of the relationship of milk production and lesion heritabilities. These results provide no convincing evidence that milk production levels offer a significant explanation for differences in risk of disease. Specifically, the probability for hoof lesions in a low-producing cow is approximately equivalent to that in a high-producing cow. Thus, the high heritability for these lesions when accounting for milk production suggests successful separate and simultaneous selection. Minimizing the incidence of lameness-causing lesions through either genetic selection or management would benefit the dairy industry. Additionally, the occurrence of some hoof lesions may reflect susceptibility to infection; identifying genetically superior animals for hoof health may also result in overall improved immune function. Further, many lesions are correlated (Koenig et al., 2005), and genetic or management improvement in one may result in improvement in another. Reducing those hoof lesions that result in lameness will improve milk yield, may result in greater longevity in the herd, may reduce the economic inputs for replacement heifers, and will improve overall animal well-being.

\section{CONCLUSIONS}

Evaluation of hoof lesion data from 3 California dairies suggests a genetic component to the expression of foot warts and sole ulcers in the dairy cow and indicates that risk of these hoof lesions is not a consequence of milk production. The moderate heritabilities of these 2 lesions indicate that concerted selection may reduce the prevalence of these lameness-inducing lesions.

\section{ACKNOWLEDGMENTS}

The authors thank the participating dairies and the hoof trimmer, David Bem (Bovine Claw Care, Escalon, CA), for their vital role in this study. Research was supported by W. K. Kellogg Endowment and ANR Competitive Grant 11-1062. The authors gratefully acknowledge Amy Achille, Alyssa Hamlin, and Crystal Teng (all of University of California, Davis) for data entry, and the infrastructure support of the Department of Animal Science, College of Agricultural and Environmental Sciences, and the California Agricultural Experiment Station of the University of California-Davis.

\section{REFERENCES}

Berry, S. L. 2001. Diseases of the digital soft tissues. Vet. Clin. North Am. Food Anim. Pract. 17:129-142.

Boettcher, P., J. Dekkers, L. Warnick, and S. Wells. 1998. Genetic analysis of clinical lameness in dairy cattle. J. Dairy Sci. 81:11481156.

Buch, L., A. Sorensen, J. Lassen, P. Berg, J. A. Eriksson, J. Jakobsen, and M. Sorensen. 2011. Hygiene-related and feed-related hoof diseases show different patterns of genetic correlations to clinical mastitis and female fertility. J. Dairy Sci. 94:1540-1551.

Buitenhuis, A. J., M. S. Lund, J. R. Thomasen, B. Thomsen, V. H. Nielsen, C. Bendixen, and B. Guldbrandtsen. 2007. Detection of quantitative trait loci affecting lameness and leg conformation traits in Danish Holstein cattle. J. Dairy Sci. 90:472-481.

California Dairy Herd Improvement Association. 2010 Annual Production Summary-All herds, all cows. Accessed Aug. 31, 2012. http:// www.cdhia.org/Annual_Summaries/index.html.

Cha, E., D. Bar, J. Hertl, L. Tauer, G. Bennett, R. González, Y Schukken, F. Welcome, and Y. Gröhn. 2011. The cost and management of different types of clinical mastitis in dairy cows estimated by dynamic programming. J. Dairy Sci. 94:4476-4487.

Cook, N. B., and K. V. Nordlund. 2009. The influence of the environment on dairy cow behavior, claw health and herd lameness dynamics. Vet. J. 179:360-369.

Ettema, J. F., and S. Ostergaard. 2006. Economic decision making on prevention and control of clinical lameness in Danish dairy herds. Livest. Sci. 102:92-106.

Evans, N. J., J. M. Brown, I. Demirkan, P. Singh, B. Getty, D. Timofte, W. D. Vink, R. D. Murray, R. W. Blowey, and R. J. Birtles. 2009. Association of unique, isolated treponemes with bovine digital dermatitis lesions. J. Clin. Microbiol. 47:689-696.

Fjeldaas, T., A. Sogstad, and O. Osteras. 2011. Locomotion and claw disorders in Norwegian dairy cows housed in freestalls with slatted concrete, solid concrete, or solid rubber flooring in the alleys. J. Dairy Sci. 94:1243-1255.

Galindo, F., and D. M. Broom. 2002. The effects of lameness on social and individual behavior of dairy cows. J. Appl. Anim. Welf. Sci. $5: 193-201$.

Gelman, A., and D. B. Rubin. 1992. Inference from iterative simulation using multiple sequences. Stat. Sci. 7:457-472.

Green, L., V. Hedges, Y. Schukken, R. Blowey, and A. Packington. 2002. The impact of clinical lameness on the milk yield of dairy cows. J. Dairy Sci. 85:2250-2256.

Hadfield, J. D. 2010. MCMC methods for multi-response generalized linear mixed models: The MCMCglmm R package. J. Stat. Softw. $33: 1-22$.

Harder, B., J. Bennewitz, D. Hinrichs, and E. Kalm. 2006. Genetic parameters for health traits and their relationship to different persistency traits in German Holstein dairy cattle. J. Dairy Sci. 89:3202-3212.

Koenig, S., A. Sharifi, H. Wentrot, D. Landmann, M. Eise, and H. Simianer. 2005. Genetic parameters of claw and foot disorders estimated with logistic models. J. Dairy Sci. 88:3316-3325.

Laursen, M., D. Boelling, and T. Mark. 2009. Genetic parameters for claw and leg health, foot and leg conformation, and locomotion in Danish Holsteins. J. Dairy Sci. 92:1770-1777.

Main, D., Z. Barker, K. Leach, N. Bell, H. Whay, and W. Browne. 2010. Sampling strategies for monitoring lameness in dairy cattle. J. Dairy Sci. 93:1970-1978.

Plummer, M., N. Best, K. Cowles, and K. Vines. 2006. CODA: Convergence diagnosis and output analysis for MCMC. R News 6:7-11.

R Development Core Team. 2011. R: A language and environment for statistical computing. http://www/R-project.org. R Foundation for Statistical Computing, Vienna, Austria. 
Shook, G. 2006. Major advances in determining appropriate selection goals. J. Dairy Sci. 89:1349-1361.

Sogstad, Å. M., T. Fjeldaas, O. Østerås, and K. Forshell. 2005. Prevalence of claw lesions in Norwegian dairy cattle housed in tie stalls and free stalls. Prev. Vet. Med. 70:191-209.

Sorensen, D., and D. Gianola. 2002. Likelihood, Bayesian and MCMC Methods in Quantitative Genetics. Springer-Verlag, New York, NY.

Tadich, N., E. Flor, and L. Green. 2010. Associations between hoof lesions and locomotion score in 1098 unsound dairy cows. Vet. J. 184:60-65.

van der Linde, C., G. de Jong, E. Koenen, and H. Eding. 2010. Claw health index for Dutch dairy cattle based on claw trimming and conformation data. J. Dairy Sci. 93:4883-4891. van der Waaij, E., M. Holzhauer, E. Ellen, C. Kamphuis, and G. De Jong. 2005. Genetic parameters for claw disorders in Dutch dairy cattle and correlations with conformation traits. J. Dairy Sci. 88:3672-3678

Walker, S., R. Smith, J. Routly, D. Jones, M. Morris, and H. Dobson. 2008. Lameness, activity time-budgets, and estrus expression in dairy cattle. J. Dairy Sci. 91:4552-4559.

Ward, W. 2009. Why is lameness in dairy cows so intractable? Vet. J. 180:139-140

Weigel, K. A. 2006. Prospects for improving reproductive performance through genetic selection. Anim. Reprod. Sci. 96:323-330.

Zink, V., J. Lassen, and M. Stipková. 2011. Genetic parameters of female fertility and udder conformation traits in the Czech Holstein cattle population. J. Dairy Sci. 94:5176-5182. 